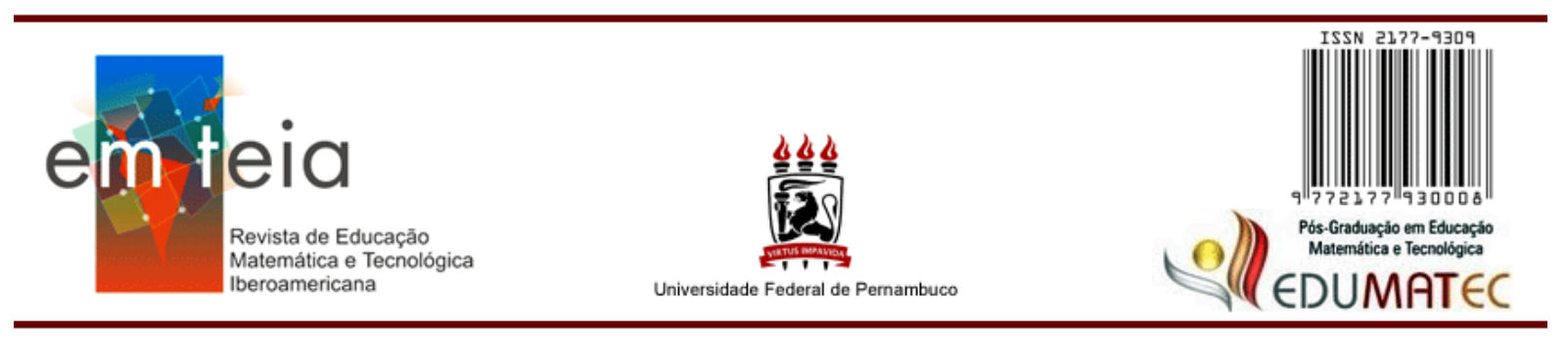

\title{
O QUE ESTUDANTES DO ENSINO MÉDIO ENTENDEM SOBRE EDUCAÇÃO FINANCEIRA?
}

\author{
WHAT DO HIGH SCHOOL STUDENTS UNDERSTAND ABOUT \\ FINANCIAL EDUCATION?
}

\author{
Jessica Barbosa da Silva \\ Doutoranda em Psicologia Cognitiva \\ Universidade Federal de Pernambuco - Pernambuco - Brasil \\ jjessicabarbosa@hotmail.com \\ http://orcid.org/0000-0001-5412-3311
}

Sintria Labres Lautert

Doutorado em Psicologia Cognitiva Universidade Federal de Pernambuco - Pernambuco - Brasil sintria.lautert@ufpe.br http://orcid.org/0000-0002-7732-0999

\begin{abstract}
Resumo
O presente estudo exploratório e de caráter qualitativo investigou o que estudantes do Ensino Médio entendem sobre Educação Financeira. Participaram da pesquisa 123 estudantes do $1^{\circ}, 2^{\circ}$ e $3^{\circ}$ anos do Ensino Médio de duas escolas públicas do estado de Pernambuco, sendo uma de ensino regular e uma de nível técnico. Como recurso metodológico foi aplicado, com os estudantes, um questionário online através do Google Forms com cinco perguntas abertas. Na sequência foram realizadas as análises das respostas dos formulários. Os resultados indicam que os estudantes têm uma compreensão sobre a temática circunscrita ao gerenciamento de finanças pessoais, e com base nesse entendimento os mesmos se consideram educados financeiramente ou não. Os estudantes consideram ainda que é importante estudar sobre a temática na escola e compreendem que o ambiente educacional deveria se responsabilizar pelo estudo da mesma. A construção de uma Educação Financeira Escolar efetiva está diretamente relacionada ao conhecimento sobre a temática, indicando um passo muito importante rumo a uma mudança de pensamento e comportamento no que tange a essa temática.
\end{abstract}

Palavras-Chave: Educação Financeira Escolar. Ensino Médio. Matemática. Educação Matemática. Estudantes.

\begin{abstract}
This exploratory and qualitative study investigated what high school students understand about Financial Education. A total of 123 students from the 1st, 2nd and 3rd years of high school from two public schools in the state of Pernambuco participated in the research, one of them being a regular school and one a technical level. As a methodological resource, an online questionnaire was applied with the
\end{abstract}


students through Google Forms with five open questions. Subsequently, the analysis of the responses to the forms was carried out. The results indicate that students have an understanding of the subject limited to the management of personal finances, and based on this understanding, they consider themselves financially educated or not. The students also consider that it is important to study about the theme at school and understand that the educational environment should be responsible for studying it. The construction of an effective School Financial Education is directly related to the knowledge on the theme, indicating a very important step towards a change in thinking and behavior regarding this thematic.

Keywords: Financial Education. High School. Mathematics. Mathematics Education. Students.

\section{Introdução}

A temática Educação Financeira (EF) faz parte da maioria dos currículos escolares dos países desenvolvidos (SILVA; POWELL, 2016). No Brasil, apesar de haver um crescimento de discussões e iniciativas acerca do tema, o ensino da mesma nas escolas ainda está em processo de implantação, ou até mesmo de elaboração, no que tange às recentes orientações pedagógicas como as propostas pela Base Nacional Comum Curricular - BNCC em 2018. Apesar do crescimento de pesquisas na área, a elaboração de um programa de EF que seja eficaz e englobe todos os temas relevantes que precisam ser discutidos ainda é um desafio.

Com a implantação da Estratégia Nacional de Educação Financeira (ENEF) através do Decreto Presidencial n ${ }^{\circ}$ 7.397, em 2010 (BRASIL, 2010), como uma política de Estado permanente, e mais recentemente, a EF como tema integrador na BNCC (BRASIL, 2018), os programas de EF voltados para o âmbito escolar começaram a aumentar, assim como as críticas sobre a sua elaboração. Diversos fatores podem estar relacionados à dificuldade de pensar em uma EF universal que seja eficaz, ainda mais se tratando de realidades tão diversas quando pensamos na pluralidade das escolas, seus contextos e suas especificidades em nosso país.

Dessa forma, boa parte das pesquisas, acerca desta temática, está direcionada à tentativa de melhorar a atuação do professor, sua formação e compreensão da mesma (BARONI; MALTEMPI, 2019; MELO, 2019), além de estudos com foco em materiais didáticos existentes e na formulação de novos (SANTOS; PESSOA, 2018, 2019; SILVA; SELVA, 2018), com o objetivo de compreender a temática e buscar a melhor forma de intervir de forma a garantir uma Educação Financeira Escolar (EFE) mais completa e que melhor atenda às diversas demandas da sociedade. Visando ampliar as reflexões sobre essa temática, o presente estudo investiga o que estudantes do Ensino Médio entendem sobre EF. Esse entendimento pode proporcionar aos professores, que estão em exercício de sala de aula, um direcionamento sobre o que trabalhar 
com os estudantes, além de auxiliar novas pesquisas que objetivam formular iniciativas e intervenções em EFE.

\section{Educação Financeira: como está sendo trabalhada em algumas escolas?}

A dificuldade de uma Educação Financeira eficaz no ambiente escolar se mostra tão preocupante quanto o desconhecimento sobre a temática por boa parte dos cidadãos brasileiros. O processo de educar financeiramente a população, apesar de ser uma preocupação mundial, parece estar mais desenvolvido em países membros da Organização para Cooperação e Desenvolvimento Econômico (OCDE), órgão que tem como propósito fomentar e promover políticas públicas voltadas ao desenvolvimento econômico e promover o bem-estar social da população mundial, como Estados Unidos, Reino Unido, Canadá, Austrália e Nova Zelândia. A organização criou em 2003 um projeto chamado Financial Education Project em resposta às preocupações dos governos da OCDE sobre os possíveis efeitos adversos dos baixos níveis de Educação Financeira da população, e com objetivo de propor programas de EF aos seus paísesmembros.

O primeiro estudo sobre a temática intitulado "Melhorando a Alfabetização Financeira: Análise de Questões e Políticas", realizado pela OCDE (2005), identificou e analisou a alfabetização financeira nos países membros da organização, destacando as mudanças econômicas, demográficas e políticas que tornam a EFE cada vez mais importante. Em junho de 2015, o Brasil e a OCDE assinaram um acordo de cooperação, que permitiu aprofundar e sistematizar o relacionamento bilateral. O acordo institucionaliza a participação brasileira em diversos foros da OCDE. Dentre uma série de recomendações apontadas pelo relatório, destacase a de que os programas de Educação Financeira devem focar nas prioridades de cada país, além de que deve começar na escola (OCDE, 2005).

Pensando em países que avançaram acerca da temática, nos Estados Unidos os programas de EF já existem desde, pelo menos, a década de 80 no século XX. De acordo com Silva e Powell (2016), desde 1984 os estudantes do Ensino Médio (high school) dos 50 estados americanos possuem um programa de planejamento financeiro nas escolas.

Desde então, várias outras iniciativas foram implementadas nos Estados Unidos, como a Jump Start Coalition for Personal Financial Literacy em 1995, com o objetivo de avaliar a educação financeira dos jovens, assim como promovê-la nas escolas; a criação de um currículo denominado Money Math: Lessons for Life com a proposta de utilizar situações reais de finanças pessoais para ensinar conceitos matemáticos e finanças pessoais para estudantes da $7^{\mathrm{a}}$ 
à $9^{a}$ série, em 2001; o White Paper, um documento oficial publicado pelo governo para servir de guia sobre a implementação da EF nos currículos escolares integrada à Matemática e à Leitura, publicado em 2002, pelo Departamento do Tesouro.

Em 2003, o Congresso Americano criou, via decreto de lei, uma comissão governamental para tratar da educação financeira dos cidadãos intitulada "Financial Education and Literacy Commission" (Comissão de Educação e Literacia Financeira), em que foram conferidas as atribuições de desenvolver uma estratégia nacional para promover a educação financeira para a população, mas apenas em 2006 a comissão publicou um plano abrangente que incluiu a educação financeira do jardim da infância ao Ensino Superior (U.S. DEPARTMENT OF THE TREASURY, 2006; MUNDY, 2008; SILVA; POWELL, 2016).

Nota-se que os Estados Unidos iniciaram ações acerca da EF há mais tempo do que boa parte dos outros países. Isso explica o porquê de a EF estar disseminada nas escolas de todo o país. A nível nacional, apenas em 2010, no Brasil, foi instituída uma política de Estado permanente acerca da temática, Estratégia Nacional de Educação Financeira (ENEF), a fim de contribuir para o fortalecimento da cidadania e fornecer ações que pudessem dar suporte à população para tomar decisões financeiras mais conscientes. Seu foco direciona-se ao desenvolvimento e à implementação de programas para três públicos-alvo: crianças, jovens e adultos. Seu objetivo é desempenhar um trabalho, principalmente, através de programas a serem desenvolvidos em escolas de Ensino Fundamental e Médio, sob orientação do Ministério da Educação e com a colaboração das Secretarias de Educação dos estados e municípios.

Já em 2018, a Educação Financeira apareceu na BNCC como uma temática a ser estudada na escola por ser uma temática que afeta a vida humana em escala local, regional e global, devendo ser trabalhada junto com outros temas como direitos da criança e do adolescente, educação para o trânsito, educação em direitos humanos, assim como saúde, vida familiar e social, educação para o consumo, dentre outros. Sendo assim, ficando a cargo dos sistemas e redes de ensino e escolas, em suas respectivas esferas de autonomia e competência, incorporar aos currículos e às propostas pedagógicas a abordagem desses temas preferencialmente de forma transversal e integradora (BRASIL, 2018). A partir dessa visibilidade, houve um crescimento de ações voltadas à EF nos últimos anos.

Uma pesquisa realizada pelo Comitê Nacional de Educação Financeira (Conef) em 2018 identificou mais de 1.300 iniciativas de EF em todo o Brasil. Estas iniciativas incluíam escolas do ensino médio e universidades, públicas e privadas, além de associações, cooperativas e órgãos da iniciativa privada que cadastraram suas iniciativas de educação financeira no $2^{\circ}$ 
Mapeamento Nacional das Iniciativas de EF. Um resultado interessante desse levantamento foi o aumento do número de ações em escolas públicas, com o conteúdo ministrado de forma transversal, especialmente por professoras e professores de matemática. Em 2013, no $1^{\circ}$ Mapeamento Nacional, foi identificado que as iniciativas eram um pouco mais de $30 \%$; já em 2018, elas saltaram para 50\%. Dessas iniciativas mapeadas, metade são da área da educação, enquanto que em 2013 eram mais voltadas para a área financeira. Esse aumento pode estar relacionado ao engajamento do governo em parceria com as escolas e, principalmente, das reflexões advindas das pesquisas desenvolvidas no país realizadas sobre essa temática.

Outro dado importante do levantamento foi em relação à gratuidade das iniciativas. $\mathrm{O}$ número de ações gratuitas duplicou em relação ao último mapeamento, passando de 36\% para $80 \%$. Esse dado é de altíssima importância quando se pensa na democratização do acesso à informação, pois a gratuidade pode garantir que essas iniciativas também consigam atingir mais pessoas. Boa parte dessas ações foram a nível nacional e com concentração maior nas regiões Norte (33\%) e Sul (32\%). As regiões Nordeste e Centro-Oeste foram as regiões com menos ações registradas, $8 \%$ e 7\% respectivamente, indicando uma necessidade de iniciativas nessas regiões. Em relação aos temas abordados, foram contemplados alguns como consumo consciente, planejamento, poupança, crédito, empreendedorismo, direitos e deveres do consumidor, investimentos, dentre outros.

Esse levantamento traz um panorama interessante de como a EF vem sendo trabalhada pelas iniciativas, mas ainda deixa uma preocupação em relação a como ela está sendo vista no ambiente escolar, uma vez que poucas iniciativas monitoram seu impacto. O documento ainda evidencia que as Secretarias de Educação não costumam oferecer cursos de capacitação para os professores, corroborando o que afirma Muniz (2016) sobre a importância da temática ser investigada e analisada, com o objetivo de compreender como está adentrando na escola e quais as suas contribuições.

Mais recentemente, o Decreto Presidencial no 10.393, de 9 de junho de 2020 (BRASIL, 2020), instituiu a nova ENEF e o Fórum Brasileiro de Educação Financeira - FBEF, revogando o Decreto $\mathrm{n}^{\mathrm{0}} 7.397$, de 22 de dezembro de 2010 que instituiu a ENEF. O novo decreto traz um foco voltado para educação financeira securitária, previdenciária e fiscal, deixando sob responsabilidade do colegiado de articulação, FBEF, implementar e estabelecer os princípios da ENEF. O Fórum Brasileiro de Educação Financeira é composto pelo Banco Central do Brasil; Comissão de Valores Mobiliários; Superintendência de Seguros Privados; Secretaria do Tesouro Nacional da Secretaria Especial de Fazenda do Ministério da Economia; Secretaria de 
Previdência da Secretaria Especial de Previdência e Trabalho do Ministério da Economia; Superintendência Nacional de Previdência Complementar; Secretaria Nacional do Consumidor do Ministério da Justiça e Segurança Pública; e, por último o Ministério da Educação.

Com esse cenário torna-se ainda mais preocupante os passos que serão dados adiante na implementação da EF nas escolas, considerando que a educação, como principal instância impactada pelo decreto, é a que menos tem participação nas decisões. Sendo assim, é importante compreender o que vem sendo defendido como uma EF voltada para a escola.

Diversos autores (MELO, 2019; MUNIZ, 2016; SILVA, 2020) vêm se debruçando em investigações no contexto escolar com o objetivo de trazer informações e direcionamentos de como a EF pode ser trabalhada na escola, e assim passam a se referir a essa EF como Educação Financeira Escolar. Silva e Powell (2013) caracterizam a EFE como sendo uma série de informações e conhecimentos sobre o dinheiro a fim de estimular os estudantes a produzir uma compreensão sobre finanças e economia, além de torná-los aptos a analisar, fazer julgamentos fundamentados e tomar decisões críticas sobre questões financeiras que envolvam sua esfera individual e coletiva.

Partindo desse contexto, Muniz (2016) propõe quatro princípios em que, segundo ele, é possível discutir a Educação Financeira Escolar: convite à reflexão, conexão didática, dualidade e lente multidisciplinar. Para o autor, a EFE não se limita ao conhecimento e à escolha de produtos financeiros, nem apenas a prover conhecimentos e informações sobre comportamentos básicos da população diante das oportunidades do mercado financeiro.

O primeiro princípio, convite à reflexão, está relacionado a oferecer aos estudantes oportunidades de reflexão através da leitura de situações financeiras que contemplem diferentes aspectos para que pensem, avaliem e tomem suas próprias decisões. O segundo princípio, conexão didática, indica que o fato da EFE se diferenciar da Educação Financeira adotada pelos bancos, e algumas outras instituições financeiras, é porque ela se volta para as questões de ensino e aprendizagem de matemática sem desconsiderar os múltiplos contextos e áreas do conhecimento presentes na sociedade, enquanto a EF dessas instituições é voltada para questões mais puramente financeiras. Dessa forma, outros fatores relacionados ao ensino e aprendizagem devem ser considerados, sendo eles matemáticos ou não.

No que diz respeito ao princípio da dualidade, Muniz (2016) afirma que a EFE pode se beneficiar da matemática, como área científica, para entender, analisar e tomar decisões em situações financeiras, e a EF seja um cenário de aprendizagem de noções e ideias matemáticas. O quarto princípio é o da lente multidisciplinar, e o autor defende que a EFE, sendo abordada 
na perspectiva da sala de aula de matemática, pode oferecer múltiplas leituras sobre as situações financeiras. Além de aspectos financeiros e matemáticos, pode envolver aspectos comportamentais, culturais, biológicos e psicológicos, e podem ser utilizados de maneira a auxiliar os estudantes na leitura de situações de consumo, renda, investimento dentre outras.

Avançando, Pessoa, Muniz e Kistemann Jr. (2018) acrescentam que a EFE deve ser um convite à reflexão sobre o uso do dinheiro e também dos impactos de suas escolhas, estimulando, ainda, os estudantes a pensar de forma crítica aproveitando oportunidades de maneira ética e sustentável, e se defendendo das armadilhas financeiras e econômicas. Ademais, os autores pontuam que a EF precisa levar em consideração as singularidades culturais e sociais do ambiente em que as pessoas estão inseridas, incluindo seu poder aquisitivo levando-os a entender que suas escolhas financeiras podem ter impactos não apenas financeiros, mas também políticos, sociais e ambientais.

Outro fator importante enfatizado por Silva (2020) é o papel da tomada de decisão na promoção da EFE. A autora evidencia que tomar consciência dos diversos vieses cognitivos, os mesmos podem ser entendidos como erros sistemáticos nas tomadas de decisões (KAHNEMAN, 2012), que podem interferir nas decisões, têm potencial para fazer com que os jovens não caiam em armadilhas financeiras, ou pelo menos tenham conhecimento de que suas decisões nem sempre são totalmente racionais, uma vez que as decisões além de contar com as particularidades do decisor, envolvem diversos fatores relacionados ao contexto, ao momento em que a decisão está sendo tomada e todos os fatores externos.

Assim, elaborar programas de EF se revela um desafio, pois inúmeros fatores devem ser levados em consideração para que as informações e conhecimentos repassados sejam úteis para o público que se deseja atingir. Visto isso, alguns autores (FERNANDES; LYNCH; NETEMEYER, 2014; KARLAN; RATAN; ZINMAN, 2014) fazem críticas às estratégias de EF com direcionamento pedagógico por não serem suficientes para gerar mudanças no comportamento financeiro dos indivíduos. Os autores afirmam que a ideia que a EF pode proporcionar um maior conhecimento e, por consequência, melhores decisões econômicas, é limitada quando se observam os efeitos de programas específicos oferecidos.

Silva (2020) traz uma discussão relevante ao considerar que a EFE é uma temática recente, sendo assim não se pode afirmar que os programas oferecidos são ineficazes, uma vez que não existem pesquisas que investigaram os impactos dos mesmos a longo prazo. À vista disso, iniciativas de EFE precisam estar de acordo com políticas públicas que se preocupem com os problemas socioeconômicos que estamos enfrentando e que tendem a se agravar. Para 
a autora pensar na inclusão de todos os segmentos da sociedade, em especial a escola, que é um ambiente de construção de conhecimentos e preparação para a cidadania, trabalhando a EFE de forma interdisciplinar, é altamente desejável, porque envolve a compreensão de habilidades e conhecimentos que possibilitem discutir questões acerca de consumo, ética, influência da mídia, sustentabilidade entre outros.

Dessa forma, propõe-se neste trabalho evidenciar a necessidade da EFE como temática indispensável na formação dos estudantes, através da apresentação do entendimento de estudantes do Ensino Médio sobre a temática. Além de incentivar novas pesquisas que visem à formulação de iniciativas com foco nas necessidades apresentadas pelos estudantes.

\section{Procedimentos metodológicos}

Trata-se de um estudo exploratório e de caráter qualitativo; portanto, toda a análise e os resultados que serão apresentados foram feitos qualitativamente, com o objetivo de investigar o entendimento de estudantes do Ensino Médio acerca da Educação Financeira.

Participaram da pesquisa 123 estudantes do $1^{\circ}, 2^{\circ}$ e $3^{\circ}$ anos do Ensino Médio de duas escolas públicas do estado de Pernambuco, sendo uma escola de ensino regular e uma de nível técnico, com idades entre 14 e 18 anos (Média $=15$ anos e 7 meses, Desvio Padrão =9,5 meses) de ambos os sexos. As escolas foram definidas a partir do acesso das autoras a esses estudantes, assim como a quantidade de respondentes foi devido à adesão dos mesmos à pesquisa.

A coleta de dados foi realizada a partir da aplicação de um questionário online através do formulário Google (Google Forms). A plataforma permite coletar dados de forma simples, rápida e gratuita através de um link enviado aos estudantes pelos ambientes digitais. Essa forma de coletar dados tem aumentado nos últimos anos devido à facilidade e, em tempos de pandemia, se mostra como um facilitador de acesso às pessoas.

O questionário aplicado aos estudantes continha cinco perguntas abertas, nas quais os estudantes tinham o espaço de um parágrafo para escrever sua resposta. As perguntas feitas aos estudantes foram elaboradas com o objetivo de coletar informações sobre seus entendimentos acerca da EF (ver Quadro 1).

Nas orientações para responder ao questionário foi solicitado que os estudantes não fizessem nenhum tipo de pesquisa sobre o tema, e que respondessem apenas com os seus conhecimentos, bem como era enfatizado que não existiam respostas certas ou erradas, e que eles poderiam ficar à vontade em suas respostas, e utilizar exemplos se preferissem. 
A instrução dada no formulário pode ser assim resumida: "Pedimos que responda a este questionário sem fazer nenhum tipo de pesquisa, respondendo de acordo com seus conhecimentos. Não existem respostas certas ou erradas, buscamos compreender apenas suas concepções sobre o tema”.

Quadro 1 - Questões propostas na investigação.

1-Para você, o que é ser educada(o) financeiramente?

2-Você acha importante ser educada(o) financeiramente? Por quê?

3-Você gostaria de estudar Educação Financeira na escola? Por quê?

4- Em que componente curricular você acha que deveria estudar Educação Financeira?

5- Em uma escala de 1 a 5 quanto você se considera educada(o) financeiramente? (em que 1 significa pouco educado e 5 muito educado). Por quê?

Fonte: As autoras.

De posse das respostas enviadas por todos os participantes, procedeu-se à análise minuciosa para cada questão, sendo estas agrupadas em categorias que pudessem englobar as principais ideias apresentadas pelos estudantes, de forma a identificar suas concepções e entendimentos acerca do tema. Os resultados e a discussão dessa investigação são apresentados no próximo tópico.

\section{Resultados e discussão}

Questionou-se aos estudantes, inicialmente, o que é ser educada(o) financeiramente. Observou-se que, para esse questionamento, a maior parte dos estudantes relacionou ser "educada(o) financeiramente" ao uso do dinheiro e lidar com finanças. A Figura 1 ilustra algumas das respostas apresentadas pelos participantes. Foi utilizada a convenção E1: Estudante 1; E2: Estudante 2 e assim sucessivamente visando assegurar o sigilo do nome dos participantes da investigação.

Figura 1- Extratos dos protocolos da Pergunta 1.

\section{Para você, o que é ser educada(o) financeiramente?}

E1: É saber utilizar o dinheiro para algo tendo em consciência os riscos e as oportunidades que aquele ato pode causar.

E2: Acredito que ser educado (a) financeiramente é saber lidar com minhas finanças pessoais, administrar meu próprio dinheiro e fazer bom uso dele, e etc. 
E3: Ser educado financeiramente, é entender como empregar seu dinheiro de forma correta, trazendo beneficios a longo prazo, além de obter organização, estabilidade e responsabilidade financeira.

E4: É aprender a saber lidar com a parte financeira.

Fonte: As autoras.

A resposta do E4 representa a maioria das respostas observadas (56\%). Nota-se que para os estudantes saber administrar suas finanças é um indicativo de EF e suas justificativas estão fortemente relacionadas ao uso do dinheiro como forma de bem-estar econômico, com o objetivo de aproveitar oportunidades e evitar riscos. Esses resultados são semelhantes aos encontrados por Silva e Pereira (2015) que, em uma amostra de 115 estudantes do Ensino Médio de três escolas de Macapá-AM, 32,15\% entendiam que EF é saber o que fazer com o seu dinheiro. Em estudo recente, Araújo, Silva, Menezes e Mendes (2020), também, verificaram que o entendimento sobre EF de docentes e supervisores do ensino profissionalizante em Quixadá-CE está relacionado a saber gerir o dinheiro que se ganha. Tais resultados parecem indicar que o entendimento, em geral, sobre a EF recai sobre saber administrar as finanças, quer seja quando se questiona estudantes do ensino médio ou a professores que atuam nesse segmento de ensino. Entretanto, mais estudos precisam ser realizados para confirmar esses resultados, tendo em vista o tamanho da amostra e o número de escolas investigadas.

Dentro desse mesmo contexto, a pergunta dois teve o objetivo de identificar a importância de ser educado financeiramente e foi possível verificar que os estudantes apresentam focos diversos em relação ao uso do dinheiro, como pode ser observado nos extratos apresentados na Figura 2. As respostas dos estudantes indicam que, para eles, dentro do contexto de administrar as finanças, pode-se considerar pelo menos quatro temáticas: tomada de decisão; comprar/gastar/consumir; planejar/economizar/guardar; e lucro/investimento.

Figura 2 - Categorias dos extratos dos protocolos da Pergunta 2.

\begin{tabular}{|ll|}
\hline Categorias & \multicolumn{1}{c|}{ Extratos de protocolos } \\
Tomada de & $\begin{array}{l}\text { E5:Ter responsabilidade nas decisões, buscando uma } \\
\text { Decisão }\end{array}$ \\
& $\begin{array}{l}\text { E6:Você tem qualidade de vida. } \\
\text { saber com o que você vai gastar seu dinheiro e fazer isso de } \\
\text { forma consciente. }\end{array}$ \\
\hline
\end{tabular}


E7:A pessoa que toma decisões financeiras responsáveis.

Comprar/gastar/ E8:É saber lidar com o dinheiro de uma forma responsável consumir com tendo o total cuidado no que compra no que é necessário e responsabilidade o que não é.

E9:É saber como utilizar corretamente minha condição financeira, visando gastar apenas com o necessário e limitando gastos com coisas desnecessárias. Como por exemplo: gastar com saúde, alimentação e etc e limitar meus gastos com viagens, passeios e etc..

E10:Você saber gastar de forma "saudável", por exemplo ver quanto você gasta por mês, por semana, calcular o que é necessário e o que não é.

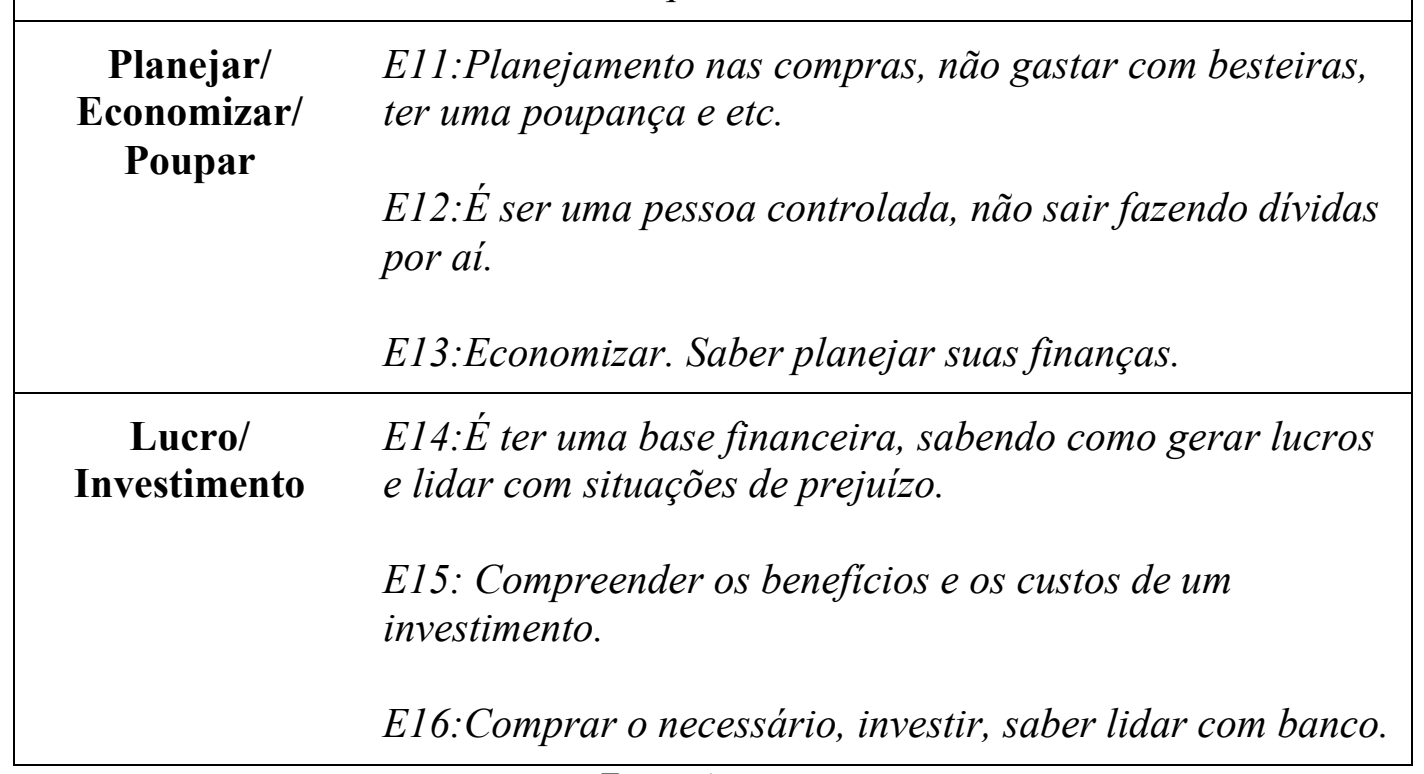
Fonte: As autoras.

As respostas apresentadas pelos participantes demonstram que eles têm uma noção mínima do que a Educação Financeira trata, ainda que, em muitos momentos, restrita a questões puramente financeiras. Pode-se notar ainda uma postura crítica diante desse aspecto. Alguns estudantes mencionaram a importância de decisões responsáveis e conscientes, uso do dinheiro de forma responsável e controlada, medo do endividamento e necessidade de evitar gastos desnecessários.

Tais respostas evidenciam um caminho possível para trabalhar a Educação Financeira a partir das concepções dos estudantes, considerando que através de suas experiências pessoais, coletivas e educacionais os mesmos conseguem fazer uma relação da EF dissociada de apenas cálculos matemáticos. 
Fazendo um diálogo com pesquisas em Educação Financeira Escolar, as concepções dos estudantes assemelham-se a de Silva e Powell (2013) que entendem que um indivíduo financeiramente educado é aquele que, diante de situações financeiras ou demanda de consumo a ser solucionada analise e avalie, de maneira coerente, as alternativas orientando sua tomada de decisão a partir de conhecimentos sobre finanças, economia e Matemática. Ainda, o mesmo deve orientar suas ações de consumo, investimento e sua tomada de decisões financeiras, operando a partir de um planejamento financeiro a curto, médio e longo prazo, tendo uma leitura crítica das informações financeiras presentes na sociedade.

Ainda assim, defende-se que embora conhecimentos sobre finanças, economia e Matemática sejam de suma importância para o estudo da em EF, a escola precisa oferecer um ambiente de reflexão, para que os estudantes pensem e analisem de forma crítica cada situação que eles podem se deparar na vida real. Os estudos mais atuais em EFE buscam exatamente trazer novas variáveis para o debate da temática, em busca de ampliar essas concepções.

Estudos que realizaram análises de livros didáticos (SANTOS; PESSOA, 2018, 2019; SILVA; SELVA, 2018) identificam a necessidade de discussões mais abrangentes sobre EFE desde os anos iniciais. Santos (2017) realizou uma categorização das atividades de EFE presentes em livros didáticos de Matemática dos anos iniciais do Ensino Fundamental na qual ela dividiu as atividades encontradas em 10 temáticas: atitudes ao comprar, influência das propagandas/mídia, guardar para adquirir bens ou produtos, desejos versus necessidades, economia doméstica, uso do dinheiro, valor do dinheiro, tomada de decisão, produtos financeiros, propaganda, sustentabilidade e consumismo.

Colocando em perspectiva as temáticas estabelecidas por Santos (2017) e os resultados dessa pesquisa, constata-se que as concepções identificadas nas respostas dos estudantes sobre a EF apontam para uma visão restrita sobre esse tema e, ao que parece, muito vinculada ao que consta nos livros didáticos que tratam sobre esse tema no contexto escolar. Sendo assim, quanto mais cedo for inserida uma EFE que promova debates, e que seja trabalhada de forma interdisciplinar, envolvendo a compreensão de habilidades e conhecimentos que possibilite discutir questões acerca de consumo consciente, tomada de decisão responsável, ética, influência da mídia, sustentabilidade dentre outros, mais cedo os estudantes terão uma compreensão mais crítica sobre a EFE.

No que diz respeito à pergunta "Você gostaria de estudar Educação Financeira na escola?”, dos 123 estudantes, 122 (99,2\%) responderam que sim. Apenas um estudante respondeu que "não sabia" e não justificou a resposta. Esse resultado é muito importante quando 
se leva em consideração que a escola também precisa estar alinhada às necessidades e aos interesses dos estudantes.

Quando questionados por que consideram importante estudar EF na escola, os estudantes apresentaram preocupações referentes ao endividamento, não saber administrar o dinheiro no futuro, fazer um planejamento financeiro e tomada de decisões responsáveis.

As respostas apresentadas na Figura 3 indicam, ainda, a expectativa desses estudantes em aprender sobre essa temática no contexto escolar (E19, E20, E23), bem como chamam atenção para o papel do professor como alguém que poderia problematizar sobre essas questões na escola (E21) contribuindo para postura mais crítica e ao mesmo tempo consciente acerca de diversas temáticas referentes à EF.

Em outras palavras, estudar EF no contexto escolar evidencia a necessidade de se olhar para as distintas realidades vivenciadas pelos estudantes e não as tratar como sendo homogêneas e representantes de uma determinada classe social, bem como é necessário explorar, de maneira interdisciplinar, diferentes temas, como sustentabilidade, ética, questões ambientais, dentre outras.

Figura 3 - Extratos dos protocolos da Pergunta 3.

\section{Por que você gostaria de estudar Educação Financeira na escola?}

E17: Porque sinto que ainda não estou totalmente preparada pra essa realidade que um dia vou ter que enfrentar, apesar de já saber um pouco sobre o assunto.

E18: Porque abrange meu conhecimento em assuntos variados, e ainda me ensina algo importante, o qual pode ser bem favorável no futuro.

E19: É importante que a escola ensine aos alunos a forma correta para administrar as suas finanças.

E20: Porque tendo esse tipo de informação desde jovem pode ajudar a ser mais consciente no futuro, facilitando na fase de independência do estudante para os gastos e investimentos.

E21: Acho isso uma coisa interessante para a vida dos adolescentes antes eu não sabia muito bem lidar com meu dinheiro mas depois do que aprendi em um trabalho que meu professor passou sobre esse assunto eu pude abrir mais a minha mente sobre essas questões e agora estou tendo mais responsabilidade com que eu gasto até para ajudar os meus pais já que eu ainda não tenho um emprego.

E22: Acho importante entender e aprender a lidar com dinheiro, porque uma hora ou outra teremos que lidar com ele e com a educação financeira nas escolas isso facilita as coisas, pois assim, somos impulsionados positivamente para um caminho por onde seguir, nos ajudando quando tivermos que conhecer esse cenário. 
E23: Toda escola, seja ela pública ou privada, deveria ensinar o valor e a importância que o dinheiro tem. Saber administrar, saber a importância, saber investir, e, saber trabalhar duro para obter o dinheiro... Abriria a mente de crianças, adolescentes, adultos e idosos.

Fonte: As autoras.

Constata-se que os estudantes apresentam relatos muito interessantes apontando a necessidade de compreender sobre o tema e reconhecendo a escola como um ambiente propício à aprendizagem dessas questões, podendo contribuir com uma formação para o futuro. Nota-se também que os estudantes não fazem referência à matemática em nenhuma de suas respostas, embora quando questionados em que componente curricular a EF deveria ser trabalhada, 74\% dos estudantes responderam que seria em Matemática, 11,3\% em Empreendedorismo, 4,9\% em Economia e 9,8\% consideram que deveria ser criada uma matéria específica para ensinar sobre a temática ${ }^{1}$.

Por fim, em resposta à pergunta "Em uma escala de 1 a 5 quanto você se considera educada (o) financeiramente? (em que 1 significa pouco educado e 5 muito educado)", mais da metade dos estudantes (52\%) marcou a Opção 3, indicando que consideram que estão no "meio termo", 29,3\% e 5,7\% dos estudantes marcaram 4 e 5 respectivamente, enquanto 9,8\% e $3,2 \%$ marcaram, respectivamente, 2 e 1 como pode ser observado no Gráfico 1.

Gráfico 1 - Em uma escala de 1 a 5 quanto você se considera educada(o) financeiramente? (em que 1 significa pouco educado e 5 muito educado)

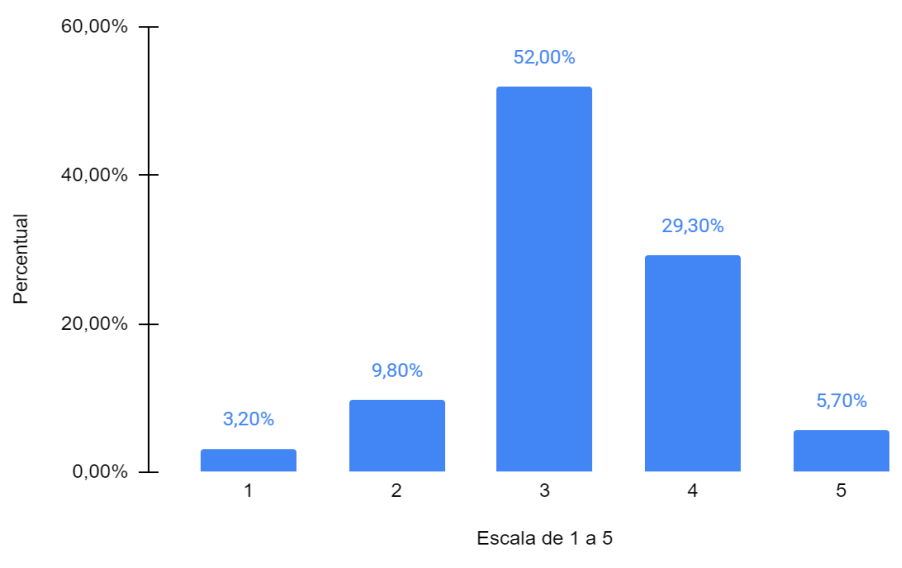

Fonte: As autoras

\footnotetext{
${ }^{1}$ Parte dos estudantes participantes são de uma Escola da Rede Técnica de ensino e estudam disciplinas de empreendedorismo e economia na área diversificada.
} 
Esses resultados evidenciam que embora os estudantes afirmem que gostariam de estudar EF na escola para aprender sobre determinados temas (investimento, consumo consciente, administrar finanças, tomar melhores decisões, dentre outros), eles ainda se consideram educados financeiramente, com base nos conhecimentos passados e hábitos que já possuem.

Esse desdobramento aponta para uma questão importante: o conhecimento que os estudantes possuem sobre EF tem uma relação direta com o seu reconhecimento como sujeito educado financeiramente, ou seja, quanto mais clara, abrangente e coerente for a compreensão dos estudantes sobre a EF, melhor e mais crítica será sua avaliação como pessoa educada financeiramente. Este resultado é reforçado quando os estudantes são questionados por que se consideram educados financeiramente, como pode ser observado nos extratos apresentados na Figura 4.

Figura 4 - Extratos dos protocolos da Pergunta 5a.

\section{5a. Por que você se considera educada(o) financeiramente?}

E24: Consigo me organizar bem e comprar o necessário e ainda ter um pouco pra gastar com "besteiras".

E25: Porque entendo a necessidade do dinheiro, e na minha situação financeira, a aquisição do dinheiro não é tão fácil, por isso, a necessidade vem acima dos desejos.

E26: Me considero educado com isso pois tenho uma valorização imensa com as remunerações que recebo quando trabalho com meu pai, tenho ciência do quanto aquilo é importante, com isso acabo valorizando o dinheiro deles também, e não querendo tudo que é mais caro, não pedindo dinheiro a eles, sim trabalhando para ter e assim vai, um exemplo disso que posso citar, foi quando minha mãe chegou com uma sandália cara e mais bonita que a outra que era mais barata, porém da mesma qualidade, e eu fiz ela devolver a mais cara kkkk pois não iria importar a beleza daquilo naquele momento (sic).

E27: Porque gasto o meu dinheiro com coisas realmente necessárias.

$$
\text { Fonte: As autoras. }
$$

Constata-se que os estudantes apresentam respostas com base nas suas experiências individuais, trazendo pensamentos interessantes relacionados ao consumo responsável, desejo versus necessidade, poupar, e valorização do dinheiro. Tais pensamentos dos estudantes são muito importantes para a construção de uma EF robusta.

Embora ainda muito relacionada a aspectos financeiros e ao uso do dinheiro, não se pode desconsiderar que tópicos relevantes de uma EF mais crítica e consciente são mencionados 
pelos estudantes. Destaca-se ainda que pensar criticamente sobre esses temas não significa deixar de consumir, ou consumir só o necessário, ou ainda sempre poupar dinheiro, mas que isso seja feito de forma responsável e consciente.

Analisando as respostas dos estudantes que se consideraram pouco educados financeiramente, nota-se que também foram relacionadas ao gerenciamento do dinheiro, deixando claro que, de maneira geral, os estudantes entendem que educado financeiramente é quem tem acesso ao dinheiro e sabe gerir suas finanças, e quem não sabe ou não administra o dinheiro não pode ser considerado financeiramente educado, como pode ser observado nos extratos de protocolos apresentados na Figura 5.

Figura 5 - Extratos dos protocolos da Pergunta 5b.

\section{5b. Por que você não se considera educada(o) financeiramente?}

E28: Porque nem dinheiro eu tenho.

E29: Hoje em dia eu gasto meu dinheiro com comida, todo dinheiro que eu pego eu acabo usando pra comprar comida (hambúrguer, pizza, pastel, etc.). Sei que deveria juntar meu dinheiro para algo que realmente preciso, algo que vá servir a longo prazo.

E30: Em uma análise individual, não tenho ideia de como administrar uma renda financeira.

E31: Eu gasto muito o meu dinheiro sem pensar direito no que estou investindo, tenho dificuldade de controlar o meu consumismo quando se trata de algo que eu acredito estar necessitando, quando na verdade era só um desejo vazio e muitas vezes já me arrependi por isso. (sic)

Fonte: As autoras.

Nota-se que o E28 considera não ser educado financeiramente simplesmente por "não ter dinheiro". Esse pensamento foi comum nas respostas dos estudantes e deixa claro que, para muitos, a EF só está relacionada ao uso do dinheiro e que quem não tem acesso a ele, não precisa de EF ou não pode ser considerado financeiramente educado.

Este pensamento pode ser considerado equivocado quando pensamos em uma EF que abrange temas relacionados à sustentabilidade, ética, meio ambiente, em uma sociedade diversa, com pessoas inseridas em múltiplos contextos que não necessariamente estão ligados ao dinheiro. Dessa forma, entende-se que a construção de uma EF efetiva está diretamente relacionada ao conhecimento sobre a temática, devendo a mesma estar devidamente pautada nos objetivos que deseja alcançar, indicando um passo muito importante rumo a uma mudança de pensamento e comportamento. 


\section{Considerações finais}

Iniciamos esse artigo buscando responder a uma questão: "Quais as concepções dos estudantes do Ensino Médio sobre Educação Financeira?". Com base nos resultados, encontrados com uma amostra de 123 estudantes, podemos afirmar que esses possuem uma compreensão de EF circunscrita ao gerenciamento de finanças pessoais, não fazendo jus aos significados que essa definição pode abarcar, conforme definições que foram citadas anteriormente (PESSOA; MUNIZ; KISTEMANN JR., 2018; SILVA, 2020). Uma possível explicação para esses resultados é que a EF ainda é uma temática recente e que programas de EF voltados para o contexto escolar, com base nas orientações dos documentos oficiais mais recentes, como a BNCC, ainda estão emergindo, portanto esses estudantes, que agora estão no Ensino Médio, ainda não vivenciaram essas transformações no espaço escolar, tendo suas concepções formuladas a partir de vivências pessoais e coletivas.

Embora as percepções trazidas pelos estudantes não contemplem aspectos como ética, sustentabilidade e influência da mídia, por exemplo, que devem ser explorados quando se discute sobre EF, eles consideram-se educados financeiramente. Nesse caso, evidencia-se a concepção majoritária presente nas questões propostas inicialmente pela OCDE, como uma EF voltada apenas para a administração das finanças e o bem-estar social da população.

Outro aspecto relevante identificado refere-se ao fato dos estudantes acharem importante estudar sobre a temática na escola e compreendem que o ambiente educacional deveria se responsabilizar pelo estudo de temáticas como esta. Quando questionados em que componente curricular deveriam estudar EF, a maior parte dos estudantes aponta a matemática como protagonista no processo, mesmo que em suas falas haja pouca referência à mesma.

Considerando os resultados deste estudo e de outras pesquisas realizadas (MELO, 2019; MUNIZ, 2016; SILVA, 2020), defende-se que os conhecimentos básicos sobre finanças pessoais pode ser um ponto de partida para a construção de uma Educação Financeira Escolar, porém ela não deve ser reduzida a isso, considerando diversos outros fatores que devem ser levados em consideração. Nesse sentido, o ambiente escolar continua sendo um lócus privilegiado para problematizar sobre esse tema, visando uma formação mais crítica e consciente sobre os limites e as possibilidades dos estudantes para lidarem com as questões que envolvem a EFE. Portanto, é necessário trazer para o contexto escolar, além de informações de como administrar o dinheiro, discussões sobre consumo consciente, influência da mídia, sustentabilidade, vieses cognitivos, desejo versus necessidade, questões ambientais dentre outros. 
Embora esta investigação traga dados que apontem a concepção de estudantes do Ensino Médio sobre essa temática, não se pode deixar de chamar atenção para as limitações que podem existir, tendo em vista que esta pesquisa foi realizada com uma amostra de estudantes do Ensino Médio de apenas duas escolas e de um mesmo município. Nesse sentido, seria pertinente ampliar a investigação com estudantes de outros níveis de ensino (Ensino Fundamental, Ensino Médio), de outras regiões do país de diferentes perfis socioeconômicos, a fim de ampliar os resultados, obter novas considerações e fazer comparações com os dados aqui apresentados.

\section{Referências}

ARAÚJO, D. S.; SILVA, A. J. N. B.; MENEZES, B. S.; MENDES, D. P. A Importância da Educação Financeira: Um Estudo no Ensino Profissionalizante. Grad Revista de Graduação USP, São Paulo. v. 4, n. 1, p. 125-137, 2020.

BARONI, A. K. C.; MALTEMPI, M. V. Os espaços da Educação Financeira na formação de professor de Matemática em uma instituição federal de São Paulo. Revemop, Ouro Preto, v. 1, n. 2, p. 248-265, 2019.

BRASIL. Estratégia Nacional de Educação Financeira - ENEF. Vida e Dinheiro, 2010. Disponível em: <http:/www.vidaedinheiro.gov.br/> Data de acesso: 02 abr. 2020.

BRASIL. Ministério da Educação. Base Nacional Comum Curricular. Brasília: MEC, 2018. Disponível em:

$<$ http://basenacionalcomum.mec.gov.br/documentos/bncc2versao.revista.pdf $>$. Data de acesso: 08 mar. 2020.

BRASIL. Presidência da República. Secretaria Geral. Estratégia Nacional de Educação Financeira - ENEF e o Fórum Brasileiro de Educação Financeira - FBEF. 2020. Disponível na internet : < http://www.planalto.gov.br/ccivil_03/_Ato20192022/2020/Decreto/D10393.htm? Data de acesso: 02 abr. 2021.

FERNANDES, D.; LYNCH, J. G.; NETEMEYER. Financial Literacy, financial education, and downstream financial behaviors. Management Science, v. 60, n. 8, p. 1861- 1883, 2014.

KAHNEMAN, D. Rápido e Devagar: duas formas de pensar. Rio de Janeiro: Objetiva, 2012.

KARLAN, D.; RATAN, A.; ZINMAN, J. Savings by the poor and for the poor: a research review and agenda. Review of Income and Wealth, v. 60, n. 1, p. 36-77, 2014.

MELO, D. P. Educação Financeira e Matemática Financeira: compreendendo possibilidades a partir de um grupo de estudo com professores do Ensino Médio. 2019 
Dissertação (Mestrado em Educação Matemática e Tecnológica) - Universidade Federal de Pernambuco - UFPE, Recife, 2019.

MUNDY, S. Financial Education Programmes. In: Schools: Analysis of Selected Current Programmes and Literature Draft Recommendations for Best Practices. OCDE Journal: General papers, v. 2008/3. OCDE, 2008.

MUNIZ, I. Jr. Econs or Humans? Um estudo sobre a tomada de decisão em Ambientes de Educação Financeira Escolar. 2016. Tese (Doutorado) - COPPE, Universidade Federal do Rio de Janeiro, UFRJ, Brasil, 2016.

OCDE. Organização de Cooperação e de Desenvolvimento Econômico. Recommendation on Principles and Good Practices for Financial Education and Awareness. 2005. Disponível em: $<$ https://www.oecd.org/finance/financial-education/35108560.pdf $>$. Acesso em: 08 set. 2020 .

PESSOA, C. A. S.; MUNIZ, I. Jr; KISTEMANN JR, M. A. Cenários sobre Educação Financeira Escolar: Entrelaçamentos entre a Pesquisa, o Currículo e a Sala de aula de Matemática. EM TEIA - Revista de Educação Matemática e Tecnológica

Iberoamericana, Recife, v. 9, n. 1, p. 1-28, 2018.

SANTOS, L. T. Educação financeira em livros didáticos de matemática dos anos iniciais do ensino fundamental: Quais as atividades sugeridas nos livros dos alunos e as orientações presentes nos manuais dos professores? 2017. Dissertação (Mestrado em Educação Matemática e Tecnológica) - Universidade Federal de Pernambuco - UFPE, Recife, 2017.

SANTOS, L. T. B.; PESSOA, C. A. S. Relações entre atividades de Educação Financeira em livros didáticos de Matemática dos anos iniciais do Ensino Fundamental e o manual do professor. Revista EM TEIA - Revista de Educação Matemática e Tecnológica Iberoamericana, Recife, v. 9, n. 3, 2018.

. Atividades de Educação Financeira a partir da perspectiva dos Ambientes de Aprendizagem de Skovsmose. Educação Matemática Pesquisa: Revista do Programa de Estudos Pós-Graduados em Educação Matemática. São Paulo. v. 21, n. 2, p. 130-151, 2019.

SILVA, A. M.; POWELL, A. B. Um programa de Educação Financeira para a Matemática escolar da Educação Básica. In: XII ENCONTRO NACIONAL DE EDUCAÇÃO MATEMÁTICA - XI ENEM, 2013, São Paulo. Anais...São Paulo, 2013.

. Currículos de Educação Financeira para a escola nos Estados Unidos.

Revista de Educação, Ciências e Matemática, Rio de Janeiro, v. 6, n. 3, set/dez 2016.

SILVA, I. T.; SELVA, A. C. V. Programa de educação financeira nas escolas - ensino médio: uma análise das orientações contidas nos livros do professor e suas relações com a matemática. REnCiMa: Revista de ensino e ciências da matemática, v. 9, n. 1, p. 140-157, 2018. 
SILVA, J. B. Heurísticas nas tomadas de decisões de estudantes do Ensino Médio frente a situações financeiras. 2020. 108p. Dissertação (Mestrado em Psicologia Cognitiva) Universidade Federal de Pernambuco - UFPE, Recife, 2020.

SILVA, T. C.; PEREIRA, W. A. Educação Financeira para alunos do Ensino Médio em Macapá-ap. Trabalho de Conclusão de Curso em licenciatura plena em Matemática. Universidade Federal do Amapá, Macapá, 2015.

U.S. DEPARTMENT OF THE TREASURY. Taking Ownership of the Future: The National Strategy for Financial Literacy. 2006. Disponível em:

$<$ https://www.treasury.gov/about/organizational-structure/offices/Domestic-

Finance/Documents/Strategyeng.pdf $>$ Data de acesso: 08 set. 2020.

VIDA E DINHEIRO. Mapeamento Nacional 2018. In: $2^{\circ}$ Mapeamento Nacional das Iniciativas de Educação Financeira: Mapeamento Nacional 2018. [S. 1.], 2018. Disponível em: http://www.vidaedinheiro.gov.br/2- mapeamento/. Data de acesso: 22 set. 2020. 